\title{
Philosophical aspect of understanding addictive behavior determinants
}

\author{
Natalia M. Chepurnova - Valery V. Grebennikov - Yuliia V. Sukhostavska - \\ Teymur E. Zulfugarzade - Stanislav I. Buslaev
}

DOI: 10.18355/XL.2018.11.01.06

\begin{abstract}
The present situation in Russia is characterized by the fact that the number of young people particularly susceptible to developing addictions like alcoholism and drug addiction is continuously growing, and this cannot but adversely affect their socialization, the way they learn and follow the norms and beliefs of society, and increases the risk of further development of this tendency in the country. The purpose of this study was to examine and elucidate the addictive behavior determinants from the standpoint of social philosophy and social psychology. The major approach to explore the problem is a systemic-activity based approach that allowed us to consider determination problem and causality of addictive behavior on the basis of people's involvement into certain types of activities that contribute to the formation of addictive behavior. The paper discusses the main challenges that human civilization faces, changes in the industrial and information age, as well as the challenges that people face in the rapidly changing conditions and forms of their own lives and activities. all negative factors that cause dissatisfaction and collapse of person's identity like loss of values once considered positive and conventional, spiritual and emotional crisis, lack of clear prospects and confidence in the future, growing individualism, selfishness, and hedonism, contribute into creating a fertile ground for addictive behavior spread. Addictive behavior is understood as a specific kind of activity, the social importance of which is negative and destructive, but it is of special significance for the people involved in it.
\end{abstract}

Key words: addictive behavior, theoretical and philosophical analysis, personal determinants, social determinants, young people

\section{Introduction}

The importance and topicality of considering addictive behavior determinants are determined by the fact that despite all efforts to prevent alcohol and drug addictions in Russia the situation, unfortunately, has not shown a great improvement. For example, by the end of 2016, the situation with drug addiction as one of the most devastating types of addictions in Russian Federation had been estimated as tough (and even ominous). According to the data presented in the Report on the Drug Situation in the Russian Federation in 2016 by the State Anti-Drug Committee, there had been no significant changes in illicit trafficking, and drug consumption noticed. Moreover, the report stated that about $40 \%$ (in 2015 they were $42.8 \%$ ) of experienced drug users first tried them at the age of 16-18. Almost one in five $(18.8 \%$; in $2015-19.9 \%)$ of drug users started using drugs at the age of 15 years, and over $72 \%$ (in $2015-71.9$ $\%$ ) at the age of 16 to 25 . This tendency poses a serious threat to modern Russian society (Report on Drug Situation in the Russian Federation in 2016, 2017).

Our attempts to discuss the philosophical understanding of the concept of existence and spread of addictive behavior through society have led to the discovery that none of the Russian philosophical encyclopedic dictionaries gives an explanation of such phenomena as "addiction," "drug abuse," alcoholism."

Addictive behavior is commonly discussed by narcologists, psychiatrists, psychologists, a social psychologist, and sociologists. In a general sense, addictive behavior is understood as a form of destructive behavior. The essence of the addictive

XLinguae, Volume 11 Issue 1, January 2018, ISSN 1337-8384, eISSN 2453-711X 
behavior is that people are trying to escape from reality artificially change their mental state by taking certain substances or permanently focusing their attention on a certain subject or activity which is able to develop intensive emotions (Mendelevich, 2007). The addictive inclination of a person refers to the tendency to be unconsciously selective in performing a certain addictive action. It is an incentive for further development or intensification of addiction or abuse which is based on the individual's constant need to achieve the anticipated psychological state by taking addictive substances, doing special addictive things or using them (Cheverikina, 2017).

Factors contributing to addiction development are different. Some researchers suggest a simple set of adverse social factors and individual personality features; some try to make sense of working out a system from the standpoint of their scientific area and this significantly affects, narrows, the range of the factors considered by them; some are trying to make global generalizations blurring the essence and outline of the problem. Most often, researchers consider the following groups of factors to determine the behavior of the individual: the external conditions of the physical environment; the external social conditions; hereditary, biological and constitutional backgrounds; and intrapersonal contributors and mechanisms of addictive behavior (Zmanovskaya, 2004). But herewith there have been no attempts made in this country to provide a deep and essential investigation into the addictive behavior.

It is apparent from the foregoing that theoretical and philosophical background needed to understand the nature of addictive behavior, its determinants, and consequently, contribute to its prevention, has been insufficiently elaborated in Russia. Such a state of things, on the one hand, reduces preventive measures effectiveness, and on the other hand, increases the importance of the research discussed here.

\section{Research Methodology \\ General philosophical laws}

In this study, we relied on the derivative laws: the law of dialectical synthesis (negation of the negation), the law of transformation of quantity into quality, and dialectical contradiction.

\section{Philosophical principles}

We proceeded from the principle of determinism, the essence of which is that there is a natural and necessary dependence of the phenomena on factors that have contributed to their appearance. Determinism includes causality with the following characteristics: 1) production relations- as the relationship between cause and effect, not just as cause preceding effect;

2) temporary asymmetry- assumes that causes precede their effects, and not vice versa;

3) the need- regardless of location in space and time the result necessarily comes, equal causes produce equal effects;

4) spatial and temporal continuity - a chain of events in cause-effect relationship occurring in space and time (Alekseev P. V., Panin A.V., 2003).

\section{Theoretical approaches}

A leading approach to study the problem is a systemic activity-based approach. In this approach, activity is considered as one of the types of active human existence which are primarily focused on creative transformation and reality cognition. Only through cognitive activities, an individual develops his consciousness and the human psyche, and it is through activities that they manifest themselves. In other words, the human psyche and activities are interrelated, and not isolated from each other. An activity has the following characteristics:

- a human is not born capable of all activities, they are learned over a whole period of the human's socialization (education and training); 
- a person carrying out any activity is able to go beyond the limits of his consciousness, create spiritual and material values, which in turn contributes to historical development and progress of the society;

- it meets the needs of a human: natural, cultural, cognitive, etc.

- it is productive; participating in it people create new ways helping in meeting their needs (Rubinstein, .2012).

Specific scientific methods

In our study, we used the method of text analysis, content analysis, synthesis of ideas developed by researchers who studied this problem, i.e., studied specific approaches to solve the problems.

\section{Results \\ Philosophical approaches to understand addictive behavior determinants in the XIX and $X X$ centuries}

From the point of view of the philosophy of the XIX-XX Centuries, the causes of addictive behavior are, first and foremost, associated with distortion of philosophical concepts. The person who is aware of his personal weakness in the society (unemployment, economic and financial problems, insecurity, war threat, etc.) sees his future dismal. Besides, a lot of people are sure they can protect their mental health from destruction with the help of alcohol, smoking, drug abuse, toxicomania or other addictive behavior

The philosophy of existentialism underlines the fact that people are increasingly alienating from each other and from society, i.e., suggest the concept that people experience the social distancing between the world and themselves.

Z. Freud created a philosophical myth about a man, his life history and the burdens of civilization where there is no place for positive perspectives; and the power of destruction (and self-destruction) in the conditions of civilization brings the human mind to a dangerous brink - an endless search for pleasures (Freud, 1992).

Stanislav Grof, a researcher into the use of non-ordinary states of consciousness to explore, heal and obtain insights into the human psyche, considered the problems that stand in the way are not of economic or technological nature, but saw that the deepest sources of the global crisis lie inside the human personality and reflect the level of consciousness evolution (Grof, 1997). He insisted that the current global crisis is basically a psycho-spiritual crisis; therefore, it is hard to imagine that it could be resolved without a radical inner transformation of humanity on a large scale and its rise to a higher level of emotional maturity and spiritual awareness.

Alvin Toffler coined the term "future shock" to refer to what happens to a society when change happens too fast, which results in social confusion and normal decisionmaking processes breaking down, and predicted that the society will run itself quite nicely until young people at some distant point in the future will take over the reigns (Toffler, 2001). To survive, to avert future shock, the individual must become infinitely more adaptable and capable than ever before, find new ways to anchor ourselves, because religion, nation, community, family, or profession are now shaking under the hurricane impact of the accelerative thrust; people have to understand that it is no longer resources that limit decisions, it is the decision that makes the resources (Toffler, 2001).

According to Erich Fromm, in pre-industrial societies, people understood the meaning of their life in terms of local religious beliefs and their national or tribal life. Their traditions ensured their internal psychological protection. However, with the era of industrialization, the belief over these meanings collapsed undermining and destroying their religious belief in a Supreme Being. And people felt they had no longer the needed protection. Having lost the opportunity to appeal to the spirituality of the past, share it with other people, they found themselves abandoned to their fate.

XLinguae, Volume 11 Issue 1, January 2018, ISSN 1337-8384, eISSN 2453-711X 
This sense of isolation, being abandoned, was the main cause for psychological problems at that time, they sought for ways of escape from it even though there was the danger of losing their mind (Fromm, 1998).

Unlimited individualism and hedonism were alternatives to traditional values of Industrial Age. In particular, Arthur Schopenhauer wrote that the Human would do anything to satisfy his ego. It is obvious that every person is a compound of needs and necessities hard to satisfy. When he comes to the conclusion that all satisfactions were illusory and did not bring peace and prosperity into his life, when he is aware that every desire satisfied brings forward not a new one but again the same desire in its new form, when all the means of satisfaction have been exhausted, then man feels only his unsatisfied desire, without any conscious motive, and there comes a state of painlessness, where nothing remains to him but abandonment to boredom. What is boredom but the feeling of the emptiness of life? (Schopenhauer, 2005).

Søren Kierkegaard considered boredom, anxiety, and despair as the human psyche's major problems, and predicted the helplessness of a person who is suffering from his painful struggle to make sense of the world, uncertainty which would lead to terror, a feeling of aloneness and helplessness, and constant anxiety (Kierkegaard, 1998).

The German philosopher Friedrich Nietzsche provided a detailed diagnosis of nihilism as a widespread phenomenon of Western culture, characterized it as a condition of tension, as a disproportion between what we want to value (or need) and how the world appears to operate. When we find out that the world does not possess the objective value or meaning that we want it to have or have long since believed it to have, we find ourselves in a crisis. He used the term "Superman," German Übermensch, for the idea that influenced on Nazi ideology. Holding a pessimistic view on modern society and culture, he believed some people were able to become superior individuals through the use of willpower though, in contrast, saw a lack of intellectual progress, leading to the decline of the human species (Nietzsche, 1989).

Albert Camus introduced and developed the concept of the Absurd defined as a metaphysical tension or opposition that results from the presence of human consciousness - with its ever-pressing demand for order and meaning in life-in an essentially meaningless and indifferent universe. Camus considered the Absurd to be a fundamental and even defining a characteristic of the modern human condition; express a fundamental disharmony, a tragic incompatibility, in our existence. He drew three consequences: revolt, freedom, and passion. The higher value of human life comes from a person's experience and consciousness. With the help of the mere act of consciousness, a person transforms into a rule of life what was an invitation to death, is able to find the new meaning and purpose in life, maybe, hoping for another life (Camus, 1989).

Hence, the works of philosophers of XIX-XX centuries help us to conclude that deformation of the human mental health is closely interrelated with the growth of addictive behavior in the world. Stress has long been known to increase vulnerability to addiction. Causes of drug addictions are rooted in social and psychological nonadaptation in the conditions of the unresolved conflict with society, children or parents, losing your beloved or of losing yourself. Addiction, in this case, is the inevitable retribution of a human, his consciousness for benefits of technical progress in all its manifestations: industrialization, urbanization, rapid acceleration of the pace of life, complications of human relationships, as well as lack of spirituality, i.e., the emotional poverty of a person.

\section{Philosophical approaches to understand the determinants of addictive behavior at the end of XX and early XXI century}


In the twenty-first century, the industrial society has been increasingly becoming more and more informational. Alvin Toffler, considering a variety of aspects of human life in the information society, wrote that a new world has been developing dependent upon abstract symbols which we become increasingly immersed in. He indicated that the emerging virtual social environment is alien to us, humans, and at some level even more faceless than the environments that have existed earlier. This causes reduction of emotional ties, the depersonalization of the participants in social interactions, the demise of nuclear families, the appearance of new forms of family relations such as contractual, episodic marriages, families in which spouses live and work in different cities, etc. (Toffler, 2009).

There is also a change of social order; the generic elite of the past has been replaced by new elites, with no resources, production, and finance but with knowledge and technical competencies. The main method to enter the elite group is education, and people who cannot or are unable to obtain a sufficient level of education to be on the desired side of life can be involved into the processes of social management (Bell, 1986).

The industry has been increasingly driven by complex technological devices; administrative and financial papers have been transformed into electronic ones. This has led to a reduction of workplaces, changes in the human labor conditions. Remote employment as a form of labor mobility is becoming more and more popular since it does not require being at their workstations during certain hours (Martin, 1986).

Rapidly changing society presents us with new and complex challenges arising, requires the ability to quickly rearrange and adjust to new conditions of life. So as not everyone is capable of that, the society frustration increases, as well as the difference between norms and values of society, and the person feels disoriented and unable to adapt.

In modern society, the strategy of adaptive behavior based on passive, conformal adoption of goals and value orientations of the reference group prevails, especially if it concerns multiple virtual groups which are increasing in number and, as a consequence, give the countless opportunities for variable participation in them. The passive nature of socialization in this respect manifests the fact that adaptive human behavior in different communities increasingly resembles a "blind faith," rather than conscious conformity. Chaos, anarchy in most social spheres, and dysfunction of traditional socialization agents, inability to foresee events of their own lives could not but cause degradation of a modern man to his primitive stage when people, because of the primitiveness of their minds invented a mystical explanation of the inexplicable enigmas that violated their stability and safety (Rostovtsev, Mashanov, 2012).

Traditionally, the process of mastering various activities is associated with expansion and increase in the number of contacts of an individual with other people, i.e., with society. It is in the process of real communication that information, experience, abilities, knowledge, skills, and outcomes are being exchanged, and this is a necessary and universal condition and factor not only for socialization and social adaptation of a person but also to form and develop both the society in general and a person in particular. The modern communication is largely a coded, symbolic and simplified transfer of information. Contradictions in the interpersonal communication of the older generations and today's youth have become more severe when parents and children, teachers and students actually stop to understand each other, speak different languages, and therefore, the older generation loses its socializing function of a mentor, authority, and an expert. Non-existent and virtual characters stand for inspirational persons, personal orientations, and behavior patterns more and more often; focusing on the young people form their attitude, behavior and even

XLinguae, Volume 11 Issue 1, January 2018, ISSN 1337-8384, eISSN 2453-711X 
appearance. This is contributed by virtual communication with no perceptual and interactive aspects that greatly affect experience, knowledge and skill transfer making them scanty but very important in social life, and hinders the development of people's social roles and functions. In addition, aggravating contradictions between form, means of communication and its content and depth, as well as between the needs of an individual in obtaining important information for adaptation and socialization and a wide variety of forms of its presentation hinders proper information selection and causes cognitive dissonance and deception in an inconsistent information flow (Rostovtsev, Mashanov, 2012).

The facts described are nothing but a deep ethic problem in modern socialization and traditional society which is now losing its true spiritual roots and gradually becoming a relic of our consciousness in the endless pursuit of perfect quality of life. In such circumstances, one of the basic functions of socialization process to ensure continuity in the development and transmission of culture from generation to generation is violated. This cannot but affect the level of culture and spirituality of the modern generation. Moreover, the present circumstances influence negatively the process of a personal development considered as a social relations actor, active participator and conscious communicator (Rostovtsev, Mashanov, Hohrina, 2013).

Definitely, from a philosophical point of view, the above-mentioned features of modern social development make one of the fundamental reasons for addictive behavior to become a frequent phenomenon.

\section{Discussion}

Today understanding the nature of addictive behavior outlined the following principles:

Drug therapists' treatment approach. Therapists for alcoholics or drug abusers connect the concept of this dependency with taking specific intoxicant (drug) substances. The harmful consequences need to be treated or healed, i.e., that is, addiction occurs due to the object of addiction, and the object itself is the cause of addictive behavior (Bechtel, 1986).

Psycho-pedagogical approach. G. A. Shichko (1981) was the first scientist to study addictive behavior in this country. he considered substance dependence not as a disease that arises from taking a particular substance by a person but as a predisposition of the person to use the substance.

The psychological approach. The dependence develops because of the paucity of an individual's psychological resources. In his genesis of addictive behavior V.A. Ivanov (2006) pays primary attention to such psychological factors as behavior management training in specific situations. He considered the following causes of addictions: disorders in "self-concept" (self-esteem and self-efficacy); the ability to control one's behavioral choices; deficiency in communication skills, i.e., low empathy, low ability to communicate, understand, explain and predict others' behavior; decline in social competence, perception, and social support.

There is a tertiary socialization concept for patients with alcoholism and drug addictions, where the main causes of addictive behavior determined are related to deprivation of their basic needs; inability to gain existential values; inability in achieving one's full potential; inability to express oneself and develop one's own style and algorithm, especially in the initial period of life (Gryaznov, 2007).

The biopsychosocial model of addictive behavior based on biopsychosocial structure models of man and society seems to be interesting and important as well. It is based on an understanding of the hierarchy of human needs when the natural increase of them ranging from biological through social develops into spiritual needs. The violation of the hierarchy, proportionality, and congruence of the biopsychosocial needs of a person leads to addictive behavior. If the biological (physical) needs an 
increase in scale it causes a collapse in your health and life plans; increase in social needs is able to collapse the man-society pattern; deformation of spiritual needs destroys the very essence of a person. In the biopsychosocial approach, the fact postulated considers all addictions (chemical and behavioral) as a unity to form an algorithm for development, its mechanism, and outcome (Karpov, Korchenov, Shakirzyanov, 2011).

In Russia, a new scientific direction, sociology, appeared as interdisciplinary science to explore natural sobriety as the natural state of a human being, in contrast to chemical and other dependencies as pathologies, and develop scientifically sound ways to devise plans to maintain sobriety and preserve mental health of people in the society.

Sobriology's objective is to study alcohol, tobacco and drug abuse situation in the country, and develop ways and means to ensure that people make a commitment to a sober lifestyle (Mayurov et al., 2013).

\section{Conclusion}

Considering any human action as behavior that refers to something significant for society and a person we can state that addictive behavior is a specific kind of activity, negative and destructive if we discuss its social importance, but still is of special importance for the people involved in it.

Based on the analysis of philosophical viewpoints on the determinants of addictive behavior it is possible to conclude that the main reason for their emergence is the dissonance between the previously established world of the person and new events that he is involved in and which are caused by changes of global civilization.

Civilizational changes, both in industrial and information (postindustrial) communities lead to loss of traditional values or their conscious denial. This brings about a need to adapt and socialize in the new rapidly changing environment. As a result, there is a spiritual and emotional crisis, no internal security and clear prospects for a person's future. A person starts to feel his loneliness in the society acutely, selfishness and hedonism as modes of existence which being not satisfied lead to personal crisis.

In such circumstances, the person starts looking for adequate protection against the environment and ways to change it, rejects true reality and creates an illusion. And this provides fertile ground for developing various forms of addictive behavior as a way of escape from reality, feel pleasure, shift the focus from real events and activities which are good both for the society and the individual to a specific addiction lifestyle.

The materials of this article may be used in teaching philosophy, social psychology, addictology, as well as for various professionals engaged in the development of programs for addictive behavior prevention and better understanding not only instrumental but also, more profoundly, causes for its development.

While conducting research, we have faced new challenges and issues to be solved. Therefore, we feel the need for the research to be continued with respect to the philosophical understanding of addictive behavior, its causes and consequences; consider it as one of the most important contemporary threats, and discuss how a safe and better life in modern society could be ensured.

\section{Acknowledgement}

The work was carried out with the financial support of the Ministry of Education and Science of the Russian Federation under the Peoples' Friendship University of Russia (RUDN University) Program "5-100" among the world's leading research and educational centers for 2016-2020.

XLinguae, Volume 11 Issue 1, January 2018, ISSN 1337-8384, eISSN 2453-711X 


\section{Bibliographic references}

ALEKSEEV, P. V. - PANIN, A. V. 2003. Philosophy. Moscow: TK Velbi, Prospect. ISBN 5-98032-164-0.

BECHTEL, E. E. 1986. Prenosological forms of alcohol abuse. Moscow Medicine. ISBN: 5-7989-0176-9.

BELL, D. 1986. Social frames of information society. New technocratic wave in the West. Moscow: Progress. ISBN: 978-5-91419-101-3.

CAMUS, A. 1989. The Myth of Sisyphus. An Absurd Reasoning. Twilight of the Idols. Moscow: Politizdat. ISBN 5-250-00378-8.

CHEVERIKINA, Ye.A. 2017. The system of psychological support of individuals prone to addictions in education process. In: Modern problems of social-andhumanitarian sciences, vol. 1, n. 9, pp. 50-53 pp. ISSN: 2414-4347.

FREUD, Z. 1992. Beyond the Pleasure Principle. Moscow: Progress; Litera.

FROMM, E. 1998. Psychoanalysis and ethics. Moscow: AST. ISBN 5-15-000776-5.

GROF, S. 1997. The Cosmic Game - Explorations of the Frontiers of Human Consciousness. New York: State University of New York Press. ISBN 0-7914-38767.

GRYAZNOV, A. N. 2007. Social psychology of addictive personality. - Kazan: Medicine. ISBN 978-5-7645-0317-2.

IVANOV, V.A. 2006. On the question of dependency theory. Newspaper "Soratnik", In: People's sobriety union, n. 10, pp. 23-24. Available online: http://lido.msk.ru/nashi-metody/psixolog-drug-cheloveka/104/k-voprosu-o-teoriizavisimosti-chitat-polnostju/

KARPOV, A. M. - KORCHUNOV, V.V. - SHAKIRZYANOV G. Z. 2011. The civil self-defense against alcoholism and drug addiction. Kazan: Medical Literature. ISBN 978-5-85247-437-1.

KIERKEGAARD, S. (1998) Pleasure and duty. Rostov-on-don: "Phoenix". ISBN 5222-00327-2.

MARTIN, G. 1986. The society of telematics. The challenge of the near future. New technocratic wave in the West. Moscow: Progress. ISBN: 978-5-91419-101-3

MAYUROV, A. N. - KRIVONOGOV, V.P. - GRINCHENKO, N. A. GRINCHENKO V.I. - KARPOV A. M. - NIKOLAEV I. V. 2013. Sobriology. The science of sobering the society. Nizhny Novgorod: O. V. Gladkov's "Publishing shop". ISBN 987-5-93530-350-1.

MENDELEVICH, D. 2007. Guide for addiktology. Saint Petersburg. ISBN 5-92680543-0.

NIETZSCHE, F. (1989), Twilight of the Idols; The AntiChrist, trans. Moscow: Politizdat. ISBN 5-250-00378-8.

REPORT ON DRUG SITUATION IN THE RUSSIAN FEDERATION IN 2016. 2017. State Anti-Drug Committee. Moscow. Available online: https://гак.мвд.pф/news/item/11499495

ROSTOVTSEVA, M.V. - MASHANOV, A. A. - KHOKHRINA, Z. V. 2013. Sociophilosophical problems of personality socialization in the conditions of Informatization of the modern society. Fundamental researches, n. 6-5, pp. 12821286. ISSN: 1812-7339.

ROSTOVTSEVA, M.V. - MASHANOV, A. A. 2012. The philosophical meaning of "social adaptation" concept. In: Bulletin of Krasnoyarsk state agrarian university, $\mathrm{n}$. 6, pp. 288-293. ISSN: 1819-4036.

RUBINSTEIN, S. L. 2012. Man and the world. Saint Petersburg: Piter. ISBN 978-5459-00888-3.

SCHOPENHAUER, A. 2005. On the Freedom of the Will and On the Basis of Morality. Two fundamental problems of ethics. Moscow: AST. ISBN-5-250-01826-7. 
SHICHKO, G. A. 1981. Against the absurdity in the anti-alcohol propaganda. Available online: http://www.literatura.tvereza.info/24/Shichko/borba-sabsurdizmami.html

TOFFLER, A. 2002. Future Shock. Moscow: AST. ISBN 5-17-010706-4.

TOFFLER, A. 2009. The third wave. Moscow: AST. ISBN: 5-17-011040-5.

ZMANOVSKAYA, E. V. 2004. Deviantology (psychology of deviant behavior. Moscow: "Academy" Publishing center. ISBN 5-7695-1782-4.

Words: 4617

Characters: 31095 (17,28 standard pages)

Prof. Natalia M. Chepurnova, Dr. of Law

Department of State and Legal Disciplines

The Russian Presidential Academy of National Economy and Public Administration

82 Prospect Vernadskogo

119571, Moscow

Russia

nm.chepurnova@migsu.ru

Prof. Valery V. Grebennikov, Dr. of Law.

Department of Judiciary, Law-Enforcement and Human Rights Activity

RUDN University (Peoples' Friendship University of Russia)

6 Miklukho-Malkaya Str.

117198, Moscow

Russia

grebval@yandex.ru

Yuliia V. Sukhostavska

Department of Judiciary, Law-Enforcement and Human Rights Activity

RUDN University (Peoples' Friendship University of Russia)

6 Miklukho-Malkaya Str.

117198, Moscow

Russia

kloffka@mail.ru

Assoc. Prof. Teymur E. Zulfugarzade, $\mathrm{PhD}$

Department of Civil Law

Plekhanov Russian University of Economics Moscow

36 Stremyannyi Pereulok Str.

115093 Moscow

Russia

teymurz@yandex.ru

Assoc. Prof. Stanislav I. Buslaev, PhD

Department of Life Safety

Financial University under the Government of the Russian Federation

49 Leningradskiy Prospect

125167, Moscow

Russia

bustivan@mail.ru 